\title{
Editor's Note: Special Section on Source Code Analysis and Manipulation
}

Published online: 5 July 2019

(C) Springer Science+Business Media, LLC, part of Springer Nature 2019

Empirical Software Engineering gratefully acknowledges the editorial work of the scholars listed below on the special section entitled "Source Code Analysis and Manipulation".

\section{Coen de Roover}

Vrije Universiteit Brussel, Belgium

coen.de.roover@vub.be

\section{Jianjun Zhao}

Kyushu University, Japan

zhao@ait.kyushu-u.ac.jp

\section{David Lo}

Singapore Management University, Singapore davidlo@smu.edu.sg

This special issue contains the following three papers:

- Security code smells in Android ICC by Pascal Gadient, Mohammed Ghafari, Patrick Frischknecht, and Oscar Nierstrasz https://doi.org/10.1007/s10664-018-9673-y

- A comparison of tree- and line-oriented observational slicing by David Binkley, Nicolas Gold, Syed Islam, Jens Krinke, and Shin Yoo https://doi.org/10.1007/s10664-018-9675-9

- Semantics-driven extraction of timed automata from Java programs by Giovanni Liva, Muhammad Taimoor Khan, and Martin Pinzger https://doi.org/10.1007/s10664-01909699-5

Publisher's note Springer Nature remains neutral with regard to jurisdictional claims in published maps and institutional affiliations. 